\title{
Dysregulation of CCAAT/enhancer binding protein-alpha (CEBPA) expression in the bone marrow of acute myeloid leukemia patients
}

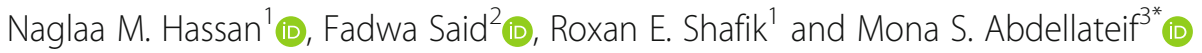

\begin{abstract}
Background: Acute myeloid leukemia (AML) is a heterogeneous malignant disease characterized by accumulation of different types of mutations commonly the CCAAT/enhancer binding protein-alpha (CEBPA). However, the dysregulations of CEBPA expression in AML is still a debatable issue. The aim of the current study was to assess CEBPA gene expression in bone marrow (BM) aspiration specimens of 91 AML patients, compared to 20 control donors of bone marrow transplantation (BMT), using RT-PCR. Data were correlated with patients' clinicopathological features, response to treatment, progression-free survival (PFS), and overall survival (OS) rates.

Results: There was overexpression of CEBPA gene in AML patients compared to normal control [1.7 (0.04-25.6) versus 0.17 (0-4.78), respectively, $P<0.001]$. Upregulation of CEBPA expression associated significantly with increased BM hypercellularity, total leucocyte counts, peripheral blood blast cell count, and poor PFS $(P<0.001,0.002,0.001$, and 0.013, respectively). There was no significant association between CEBPA expression and any other relevant clinicopathological features or OS rates $(P=0.610)$ of the patients. ROC analysis for biological relevance of CEBPA expression with AML showed that sensitivity and specificity of CEBPA expression at a cut-off value of 0.28 are $92.3 \%$ and $78.6 \%$, respectively $(P<0.001)$. All patients who had CEBPA overexpression and mutant FLT3 showed BM hypercellularity, adverse cytogenetic risk, increased TLC, and PB blast cells count $(P=0.007, P<0.001,0.016$, and 0.002 , respectively).
\end{abstract}

Conclusion: CEBPA overexpression could be used as a genetic biological marker for AML diagnosis, as well as a poor prognostic factor for disease progression. It has no impact on OS rates of the patients.

Keywords: AML, CEBPA, FLT3, Survival

\section{Background}

Acute myeloid leukemia (AML) is a heterogeneous malignant disease of hematopoietic cells that can affect children and adults [1]. It is considered one of the main causes of cancer-related death in children, and the most common acute leukemia in adults $[2,3]$. The AML is characterized by accumulation of different types of mutations; one of the most commonly affected mutations is

\footnotetext{
* Correspondence: mona.sayed@nci.cu.edu.eg

${ }^{3}$ Medical Biochemistry and Molecular Biology, Cancer Biology Department,

National Cancer Institute, Cairo University, Cairo 11976, Egypt

Full list of author information is available at the end of the article
}

CCAAT/enhancer binding protein-alpha (CEBPA) gene [4]. Other reported genes that have been associated with AML development are fins-related tyrosine kinase 3 (FLT3-ITD) and nucleophosmin 1 (NMP1), which play important roles in patients' prognosis and treatment [2]. In addition, Karyotypes of $\mathrm{t}(15 ; 17), \mathrm{t}(8 ; 21), \mathrm{t}(16 ; 16)$ or normal karyotype with double CEBPA mutation indicate favorable outcome, whereas $-5 / 5 q-,-7 / 7 q-, t(6 ; 9), \operatorname{inv}(3), t(9 ; 22), t(v ; 11 q 23)$ complex, and FLT3 mutation identified patients with high risks and poor outcomes. These patients urgently need intensive therapy especially hematopoietic stem cell transplantation (HSCT) to improve their survival [5]. The choice 
of HSCT is mainly related to the cytogenetic profile of AML patients; however, the advantage of the transplant is exclusive to those who have CEBPA mutations associated with other criteria for poor prognosis [6-8]. It has been reported that $C E B P A$ mutation is present in approximately $10 \%$ of AML patients $[9,10]$. In addition, the outcomes of HSCT remain insufficient, and more than $50 \%$ of those patients eventually die from the AML malignancy [11].

The CEBPA is a transcription factor that affects immune cells density and differentiation [12]. It is a member of the basic region leucine zipper family of transcription factors. This protein is important for the inhibition of self-renewal, cell cycle arrest, and myeloid differentiation during hematopoiesis [13]. The expression of CEBPA gene is upregulated during granulocytic differentiation and downregulated during the alternative monocytic pathway [14]. Several studies have reported the association of CEBPA expression and the prognosis of AML patients with an intermediate risk karyotype or with distinct cytogenetic risk groups $[4,9,15]$.

Although the genetic aberrations and the molecular mechanisms underlying AML had been well known, most patients still had intermediate risk and unfavorable prognosis with poor survival outcomes [16]. Therefore, the aim of the current study was to assess the expression levels of CEBPA gene in AML patients from Egypt and evaluate its diagnostic, prognostic, and predictive role(s). The data were correlated to the relevant clinicopathological features of the patients, response to treatment, progression-free survival (PFS), and overall survival (OS) rates. This may help us to categorize patients according to their clinical response to treatment and also may allow for a new targeted therapy for those patients with CEBPA overexpression.

\section{Methods}

This is a prospective cohort study included 91 patients with AML, who were presented to the Medical Oncology Department of the National Cancer Institute (NCI) during the period between 2015 to 2016, compared to 20 healthy age- and sex-matched control subjects collected from donors of bone marrow transplantation (BMT). Diagnosis was done according to WHO classification of tumors of the hematopoietic and lymphoid tissues [17]. The cytogenetic risk of the patients was done according to the 2017 European leukemia net (ELN) recommendations [5].

\section{Samples acquisition}

All patients and control subjects were presented to the Clinical Pathology Department, NCI, for bone marrow aspiration (BMA). Two drops of BMA were withdrawn to perform smear slides for morphology and cytochemistry. Two BMA specimens were collected from all patients.
The first was collected on potassium ethylene diamine tetra-acetic acid (K-EDTA) for immunophenotypic and molecular analyses. The second was collected on sodium heparin for conventional karyotyping and fluorescence in situ hybridization (FISH).

\section{RNA extraction and CDNA formation}

BMA samples $(1 \mathrm{ml})$ were obtained from the assessed patients and controls on EDTA anticoagulant tubes. Total RNA was extracted from bone marrow (BM) cells using a QIAamp RNA extraction blood mini kit (QIAG EN $^{\circ}$ Austin, TX, USA, catalog no. 52304) as recommended by the manufacturer's instructions. The purity and the concentration of the purified RNA was detected using spectrophotometer NanoDrop (Quawell, Q-500, Scribner, USA) and stored at $-80{ }^{\circ} \mathrm{C}$ till further assessments. Complementary DNA (cDNA) was prepared using high-capacity cDNA reverse transcription kit (Applied Biosystems, Thermo Fisher Scientific, USA; catalog no. 4368814) according to the manufacturer's instructions. Complementary DNA purity and concentration was assessed and then stored at $-20{ }^{\circ} \mathrm{C}$ till performing quantitative real-time PCR.

\section{Real-time PCR (RT-PCR)}

The CEBPA mRNA expression for enrolled samples was quantified using Taqman Universal PCR Master Mix II (Applied biosystems, USA, Thermo Fisher scientific, Cat no. 4440040) and CEBPA Taqman Gene Expression Assay (Applied biosystems, USA, Thermo Fisher scientific, Cat no. 4331182, Hs 00269972-S1). CEBPA expression was normalized to $B$-actin as endogenous control. Quantitative real-time PCR (QRT-PCR) was performed using cDNA with the concentration adjusted depending on the abundance of mRNA. The thermal reaction conditions were as follows: $95^{\circ} \mathrm{C}$ for $10 \mathrm{~min}$ (polymerase activation), followed by 40 cycles of $95{ }^{\circ} \mathrm{C}$ for 30 seconds (denaturation) and $60{ }^{\circ} \mathrm{C}$ for $60 \mathrm{~s}$ (annealing and extension), in which fluorescence was acquired and detected by StepOne Real-Time PCR System (Applied Biosystems, Foster City, CA, USA). The relative expression of the CEBPA gene was analyzed by the comparative $\mathrm{Ct}$ method $\left(2^{-\Delta \mathrm{Ct}}\right)$ according to Schmittgen and Livak [18].

\section{Statistical Analysis}

Data were analyzed using the SPSS package (version 22 for Windows; SPSS Inc., Chicago, IL, USA). Comparison of gene expression between patients and control was done using Mann-Whitney test. Pearson's $\chi^{2}$ was used to determine the associations between gene expression and clinico-pathological features of the patients [19]. The area under the receiver operating curve (ROC) was calculated to investigate the best cut-off value, sensitivity, and specificity for diagnosis of AML. Patients were 
classified into $C E B P A$ gene low and over expression according to the best cut-off value obtained by the ROC curve. Kaplan-Meier was used for comparing survival rates using Log-rank test. Progression-free survival (PFS) was defined as time from date of primary treatment till date of relapse/progressive disease, and overall survival (OS) is the time from date of diagnosis till date of death. $P$-values $\leq 0.05$ were considered statistically significant.

\section{Results}

\section{Patients' characteristics}

The current study included 91 AML patients with a median age of 33 years old, ranged from 18 to 65 years old. Males represented 50/91 (54.9\%), and females were 41/ 91 (45.1\%). Patients were classified according to the French-American-British (FAB) classification into M0 (1.72\%), M1 (12.1\%), M2 (41.8\%), M4 (26.4\%), M5 (18.7\%), and M7 (1.1\%). The cytogenetic risk of the patients was as follows: favorable $18(19.8 \%)$, intermediate 51 (56\%), and unfavorable 22 (24.2\%). BMA of the assessed patients showed hypercellularity in 70 (76.9\%), hypo-cellularity in 7 (7.7\%), and normo-cellularity in 14 (15.4\%) patients. Lymphadenopathy was detected in 30 (33.0\%) patients, hepatomegaly in 27 (29.7\%), and splenomegaly in 23 (25.3\%). Fourteen patients (15.4\%) had FLT3 ITD mutation and 77 (84.6\%) had wild type FLT3. The other clinico-pathological features were summarized in Table 1.

\section{Expression levels of CEBPA gene in the patients' groups}

The median expression and range of CEBPA in AML patients was $1.7(0.04-25.6)$, while it was $0.17(0-4.78)$ in the normal control group. The difference in the expression between the two groups was statistically significant $(P<0.001$, Fig. 1a).

ROC analysis was performed to assess the biologic relevance of $C E B P A$ expression for AML patients against the control group. It showed $92.3 \%$ sensitivity and $78.6 \%$ specificity at a cut-off value of 0.28 with area under curve (AUC) $0.826(P<0.001$, Fig. $1 b)$. It was noted that all patients with FLT3-ITD mutation had CEBPA expression over the cut-off value of 0.28 (Fig. 1c).

\section{Association between CEBPA expression and clinico- pathological features of the patients}

Patients were classified according to the median into 44 (48.4\%) patients with low CEBPA expression $(<1.7)$, and 47 (51.6\%) patients with CEBPA overexpression (> 1.7). There was a significant increase in the total leucocyte count (TLC) in patients with CEBPA overexpression [61 $\left.(1-440) \times 10^{9} / \mathrm{L}\right]$, compared to those with $C E B P A$ low expression [16 $\left.(2.2-240) \times 10^{9} / \mathrm{L}, P=0.002\right]$. Also, the percentage of peripheral blood blasts was significantly increased in patients with CEBPA overexpression, compared to those with CEBPA low expression [70 (0$98)$ versus $40(0-95)$, respectively, $P=0.001]$. Meanwhile, the percentage of bone marrow blasts was increased in patients with CEBPA overexpression, compared to those with CEBPA low expression [75 (3397) versus 65 (14-95), respectively]; however, this association is nearly significant $(P=0.051)$. Patients with CEBPA overexpression showed significant BM hypercellularity $(P<0.001)$, since out of all patients who had CEBPA over expression, there were $44 / 47$ (93.6\%) that showed hypercellular BM, 2/47 (4.3\%) showed normocelluar BM, and only $1 / 47$ patient (2.1\%) had hypocellular BM. However, there was no significant association between $C E B P A$ expression and any of the other relevant clinico-pathological features of the patients $(P>$ 0.05, Table 2).

Patients who had both CEBPA overexpression and mutant FLT3 showed BM hypercellularity, adverse cytogenetic risk, and increased TLC and PB blast cells count. Since, BM hypercellularity was present in $88.9 \%(8 / 9)$ of patients with CEBPA overexpression and mutant FLT3, 94.7\% (36/38) of patients with CEBPA overexpression and wild type $F L T 3,60 \%(3 / 5)$ in patients with CEBPA low expression and mutant FLT3, compared to 59\% (23/ $39)$ in patients with $C E B P A$ low expression and wild FLT3 $(P=0.007$, Fig. 2a). Also, all patients with (CEBPA overexpression and mutant FLT3) and those with (CEBPA low expression and mutant FLT3) were presented with adverse cytogenetic risk (100\% for both groups), compared to $12.8 \%$ of patients with CEBPA low expression and wild FLT3, or $7.9 \%$ of patients with CEBPA overexpression and wild FLT3 $(P<0.001$, Fig. 2b). Patients with CEBPA overexpression and mutant FLT3 had a significantly increased TLC (115, range; 1$\left.440 \times 10^{9} / \mathrm{L}\right)$, compared to those with CEBPA low expression and wild FLT3 (16.4, range; $2-403 \times 10^{9} / \mathrm{L}, P$ $=0.016$, Fig. $2 \mathrm{c}$ ). On the other side, patients with CEBPA low expression and wild FLT3 showed a significant decrease in PB blast cell count (32.5\%, range; 0-95\%), compared to the other patients' groups $(P=0.002$, Fig. 2d).

\section{Overall Survival (OS) and progression-free survival (PFS) rates of the patients}

Out of the 91 assessed AML patients, there were 68 (74.7\%) who had complete remission (CR), and 23 (25.3\%) patients had progressive disease. There was a significant association between PFS rate and CEBPA expression, since the median PFS time for patients with CEBPA low expression was 40.7 months compared to 12.4 months for patients with CEBPA overexpression ( $P=0.013$, Fig. 3a).

During the follow-up period of the patients, there were $54(59.3 \%)$ that died and $37(40.7 \%)$ alive. There was no 
Table 1 Clinico-pathological features of the assessed AML patients

Patients' characteristics
Age (median and range), years
TLC (median and range), $\times 10^{9} / \mathrm{L}$
HB (median and range), g/dl
Sex
Male
Female
BM cellularity
Hypercellular
Hypocellular
Normocellular

\section{FAB classification}

M1
M2
M4
M5
M7

\section{Organomegally}

Hepatomegaly

Spleenomegaly

CD34

Negative

Positive

CD13

Positive

\section{CD117}

$$
\begin{aligned}
& \text { Negative } \\
& \text { Positive }
\end{aligned}
$$

\section{CD14}

Negative

Positive

\section{Aberrant IPT markers}

Without aberrant marker

With aberrant marker

Response to treatment

$$
\begin{aligned}
& \text { CR } \\
& \text { No CR }
\end{aligned}
$$

PLT (median and range) $\times 10^{9} / \mathrm{L}$

BP blast (median and range) \%

BM blast (median and range) \%

\section{CD4}

$$
\text { Negative }
$$

Positive

Frequency (\%)
$33(18-65)$
$38.9(1-440)$
$8(5.5-13)$

50 (54.9)

41 (45.1)

70 (76.9)

7 (7.7)

14 (15.4)

$11(12.1)$

$38(41.8)$

24 (26.4)

17 (18.7)

1 (1.1)

27 (29.7)

$23(25.3)$

27 (29.7)

$64(70.3)$

91 (100)

19 (20.9)

$72(79.1)$

$47(51.6)$

44 (48.4)

73 (80.2)

18 (19.8)

68 (74.7)

$23(25.3)$

35 (5-297)

50 (0-98)

\begin{tabular}{|c|c|}
\hline Patients' characteristics & Frequency (\%) \\
\hline \multicolumn{2}{|l|}{ Cytogenetic risk } \\
\hline Favorable & $18(19.8)$ \\
\hline Intermediate & $51(56.0)$ \\
\hline Unfavorable & $22(24.2)$ \\
\hline \multicolumn{2}{|l|}{ IPT } \\
\hline Mono & $7(8.0)$ \\
\hline Myelo & $50(57.5)$ \\
\hline Myelomono & $29(33.3)$ \\
\hline Megakaryoblastic & $1(1.1)$ \\
\hline \multicolumn{2}{|l|}{ Lymphadenopathy } \\
\hline Negative & $61(67.0)$ \\
\hline Positive & $30(33.0)$ \\
\hline \multicolumn{2}{|l|}{ MPO } \\
\hline Negative & $3(3.3)$ \\
\hline Positive & $88(96.7)$ \\
\hline \multicolumn{2}{|l|}{ CD33 } \\
\hline Positive & $91(100)$ \\
\hline \multicolumn{2}{|l|}{ HLA/DR } \\
\hline Negative & $16(17.6)$ \\
\hline Positive & $75(82.4)$ \\
\hline \multicolumn{2}{|l|}{ CD11c } \\
\hline Negative & $52(57.1)$ \\
\hline Positive & $39(42.9)$ \\
\hline \multicolumn{2}{|l|}{ FLT3 (ITD) } \\
\hline Wild & $77(84.6)$ \\
\hline Mutant & $14(15.4)$ \\
\hline \multicolumn{2}{|l|}{ Death } \\
\hline Alive & $37(40.7)$ \\
\hline Dead & $54(59.3)$ \\
\hline
\end{tabular}

70 (14-97)

37 (40.7)
Table 1 Clinico-pathological features of the assessed AML patients (Continued)

significant association between the $O S$ rates of the patients and CEBPA expression, since the median OS time for patients with CEBPA low expression was 9 months compared to 11.4 months for patients with CEBPA overexpression ( $P=0.610$, Fig. $3 \mathrm{~b})$.

On the other hand, combined CEBPA overexpression with FLT3 mutation had no significant impact on PFS or OS rates $(P=0.081$ and $P=0.664$, respectively, Fig. 3c, d)

\section{Discussion}

Different chromosomal abnormalities and genomic alterations had been reported to play important roles in the pathogenesis of AML, especially recurrent mutations in the FLT3, NPM1, DNMT3A, and IDH1 [20]. However, many patients with AML have no mutations in any of the currently recognized genes associated with the 

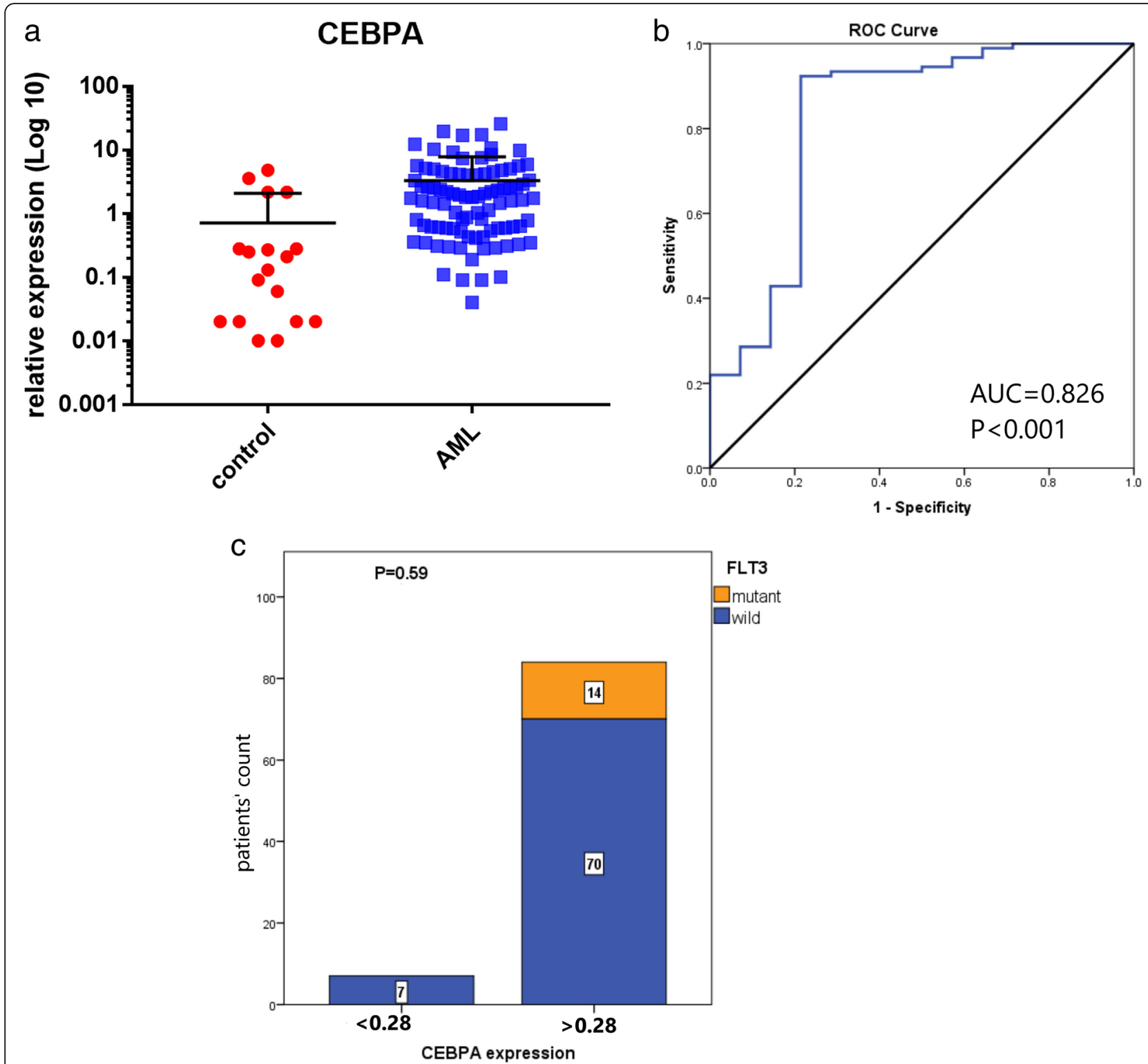

Fig. 1 a Comparative expression of CEBPA mRNA in AML patients and control group. $\mathbf{b}$ ROC analysis of CEBPA gene in AML patients compared to healthy control. c Association between CEBPA gene dysregulation and FLT3 mutation

progression of AML [21]. So it is essential to investigate other molecular aberrations that may affect the pathogenesis of AML or can predict patients' outcomes. The aim of the current study was to assess the expression level of CEBPA gene in AML patients, regarding its biological role and prognostic and predictive value(s).

The reported data in literature regarding CEBPA expression levels in AML patients is still controversial. Our results demonstrated a significant overexpression of CEBPA in AML patients compared to normal control, which confirm that this gene upregulation may have a role in the AML pathogenesis. These data are consistent with many recent published studies that reported upregulation of CEBPA in AML patients [15, 22, 23]. Mustafa et al. also determined five pathogenic CEBPA mutations using bioinformatics analysis, which could be used as genetic biomarkers for AML [11]. On the other hand, several studies reported contradictory results regarding this issue; they demonstrated that there were no significant alterations in CEBPA expression in AML patients [24-26]. This discrepancy in results may be due to the variability in the genetic makeup and the underlying etiological factors for mutations between different populations, different clinical features, sample size, and different assessment methods among studies. 
Table 2 Association between CEBPA gene expression and patients' characteristics

\begin{tabular}{|c|c|c|c|}
\hline & \multicolumn{2}{|l|}{ CEBPA expression } & \multirow[t]{2}{*}{$P$ value } \\
\hline & Low expression (44) & Overexpression (47) & \\
\hline Age (years) & $33(18-65)$ & $34(18-57)$ & 0.499 \\
\hline $\operatorname{TLC}\left(\times 10^{9} / \mathrm{L}\right)$ & $16(2.2-240)$ & $61(1-440)$ & 0.002 \\
\hline Platelet count $\left(\times 10^{9} / \mathrm{L}\right)$ & $35(7-110)$ & $34(5-297)$ & 0.799 \\
\hline HB (gm/dl) & $7.9(4.6-12.1)$ & $8(5.5-13)$ & 0.859 \\
\hline PB blast (\%) & $40(0-95)$ & $70(0-98)$ & 0.001 \\
\hline BM blast (\%) & 65 (14-95) & 75 (33-97) & 0.051 \\
\hline \multicolumn{4}{|l|}{ Gender } \\
\hline Male & $21(47.7 \%)$ & $29(61.7 \%)$ & \multirow[t]{2}{*}{0.21} \\
\hline Female & $23(52.3 \%)$ & $18(38.3 \%)$ & \\
\hline \multicolumn{4}{|l|}{ BM cellularity } \\
\hline Hypercellular & $62(59.1 \%)$ & $44(93.6 \%)$ & \multirow[t]{3}{*}{$P<0.001$} \\
\hline Hypocellular & $6(13.6 \%)$ & $1(2.1 \%)$ & \\
\hline Normocellular & $12(27.3 \%)$ & $2(4.3 \%)$ & \\
\hline \multicolumn{4}{|l|}{ FAB } \\
\hline M1 & $5(11.4 \%)$ & $6(12.8 \%)$ & \multirow[t]{5}{*}{0.77} \\
\hline $\mathrm{M} 2$ & $18(40.9 \%)$ & $20(42.6 \%)$ & \\
\hline M4 & $13(29.3 \%)$ & $11(23.4 \%)$ & \\
\hline M5 & $7(15.9 \%)$ & $10(21.3 \%)$ & \\
\hline M7 & $1(2.3 \%)$ & $0(0.0 \%)$ & \\
\hline \multicolumn{4}{|l|}{ FLT3-ITD } \\
\hline Wild & 39 (88.6\%) & 38 (80.9\%) & \multirow[t]{2}{*}{0.39} \\
\hline Mutant & $5(11.4 \%)$ & $9(19.1 \%)$ & \\
\hline \multicolumn{4}{|l|}{ Cytogenetics } \\
\hline Abnormal & $32(72.7 \%)$ & 35 (74.5\%) & \multirow[t]{2}{*}{0.85} \\
\hline Normal & $12(27.3 \%)$ & $12(25.5 \%)$ & \\
\hline \multicolumn{4}{|l|}{ Cytogenetic risk } \\
\hline Adverse & $10(22.7 \%)$ & $12(25.5 \%)$ & \multirow[t]{3}{*}{0.48} \\
\hline Intermediate & $23(52.3 \%)$ & $28(59.6 \%)$ & \\
\hline Favorable & $11(25.0 \%)$ & $7(14.9 \%)$ & \\
\hline \multicolumn{4}{|l|}{ Hepatomegaly } \\
\hline Negative & $28(63.6 \%)$ & $36(76.6 \%)$ & \multirow[t]{2}{*}{0.25} \\
\hline Positive & $16(36.4 \%)$ & 11 (23.4\%) & \\
\hline \multicolumn{4}{|l|}{ Spleenomegaly } \\
\hline Negative & $31(70.5 \%)$ & 37 (78.7\%) & \multirow[t]{2}{*}{0.47} \\
\hline Positive & $13(29.5 \%)$ & $10(21.3 \%)$ & \\
\hline \multicolumn{4}{|l|}{ Lymphadenopathy } \\
\hline Negative & 31 (70.5\%) & $30(63.8 \%)$ & \multirow[t]{2}{*}{0.51} \\
\hline Positive & $13(29.5 \%)$ & 17 (36.2\%) & \\
\hline \multicolumn{4}{|l|}{ CD34 } \\
\hline Negative & $14(31.8 \%)$ & $13(27.7 \%)$ & \multirow[t]{2}{*}{0.82} \\
\hline Positive & $30(68.2 \%)$ & $34(72.3 \%)$ & \\
\hline \multicolumn{4}{|l|}{ CD117 } \\
\hline Negative & $13(29.5 \%)$ & $6(12.8 \%)$ & \multirow[t]{2}{*}{0.07} \\
\hline Positive & $31(70.5 \%)$ & 41 (87.2\%) & \\
\hline
\end{tabular}


Table 2 Association between CEBPA gene expression and patients' characteristics (Continued)

\begin{tabular}{|c|c|c|c|}
\hline & \multicolumn{2}{|l|}{ CEBPA expression } & \multirow[t]{2}{*}{$P$ value } \\
\hline & Low expression (44) & Overexpression (47) & \\
\hline \multicolumn{4}{|l|}{ HLA/DR } \\
\hline Negative & $7(15.9 \%)$ & $9(19.1 \%)$ & \multirow[t]{2}{*}{0.786} \\
\hline Positive & 37 (84.1\%) & 38 (80.9\%) & \\
\hline \multicolumn{4}{|l|}{ CD4 } \\
\hline Negative & 27 (61.4\%) & $27(57.4 \%)$ & \multirow[t]{2}{*}{0.831} \\
\hline Positive & 17 (38.6\%) & $20(42.6 \%)$ & \\
\hline \multicolumn{4}{|l|}{ CD14 } \\
\hline Negative & $23(52.3 \%)$ & $24(51.1 \%)$ & \multirow[t]{2}{*}{0.908} \\
\hline Positive & $21(47.7 \%)$ & $23(48.9 \%)$ & \\
\hline \multicolumn{4}{|l|}{ CD11c } \\
\hline Negative & $24(54.5 \%)$ & $28(59.6 \%)$ & \multirow[t]{2}{*}{0.675} \\
\hline Positive & $20(45.5 \%)$ & $19(40.4 \%)$ & \\
\hline \multicolumn{4}{|l|}{ IPT } \\
\hline Mono & $2(4.9 \%)$ & $5(10.9 \%)$ & \multirow[t]{4}{*}{0.386} \\
\hline Myelo & $22(53.7 \%)$ & $28(60.9 \%)$ & \\
\hline Myelomono & 16 (39.0\%) & $13(28.3 \%)$ & \\
\hline Megakaryoblastic & $1(2.4 \%)$ & $0(0.0 \%)$ & \\
\hline \multicolumn{4}{|c|}{ Aberrant IPT markers } \\
\hline Negative & 38 (86.4\%) & 35 (74.5\%) & \multirow[t]{2}{*}{0.193} \\
\hline Positive & $6(13.6 \%)$ & $12(25.5 \%)$ & \\
\hline
\end{tabular}

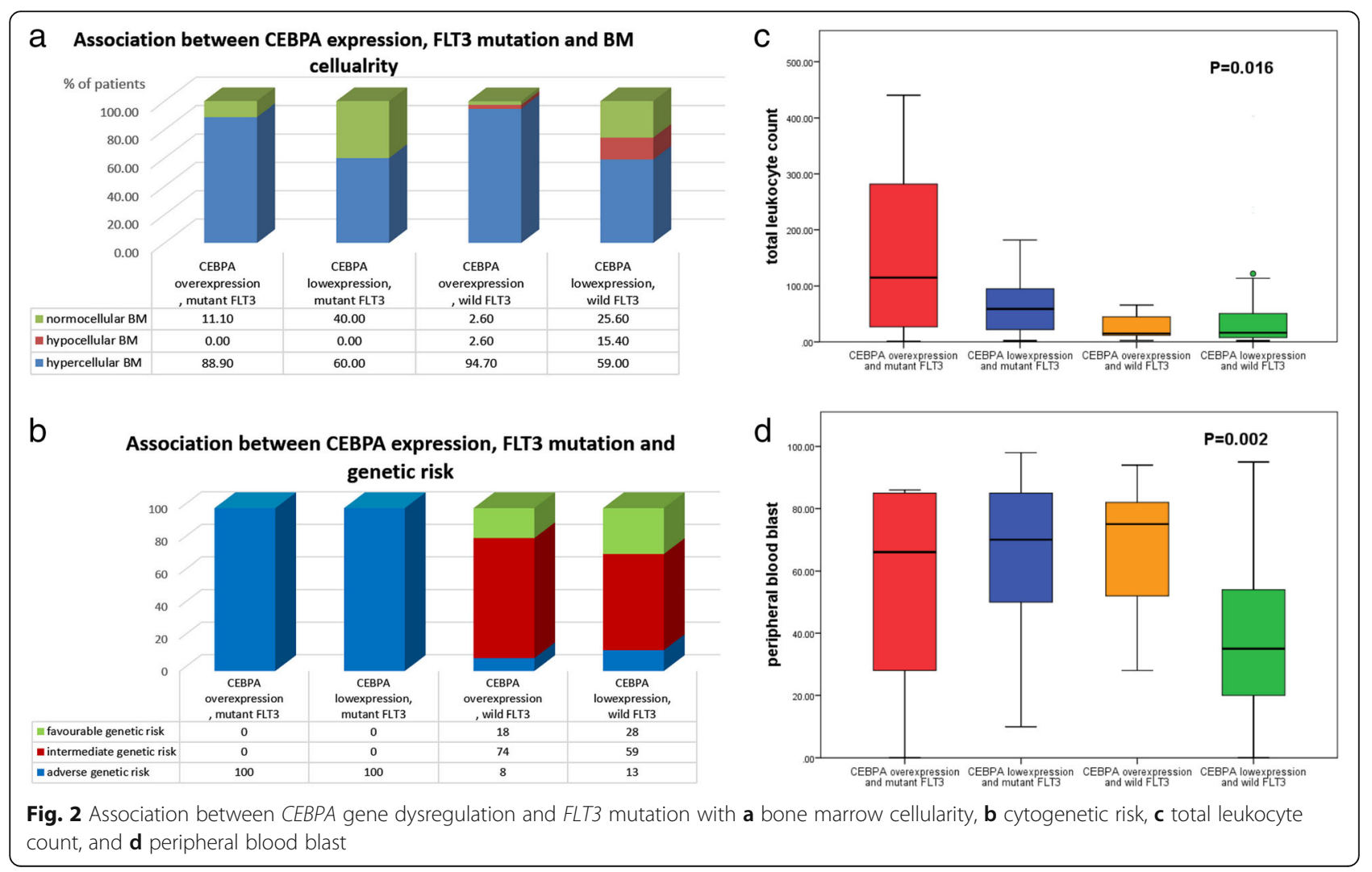



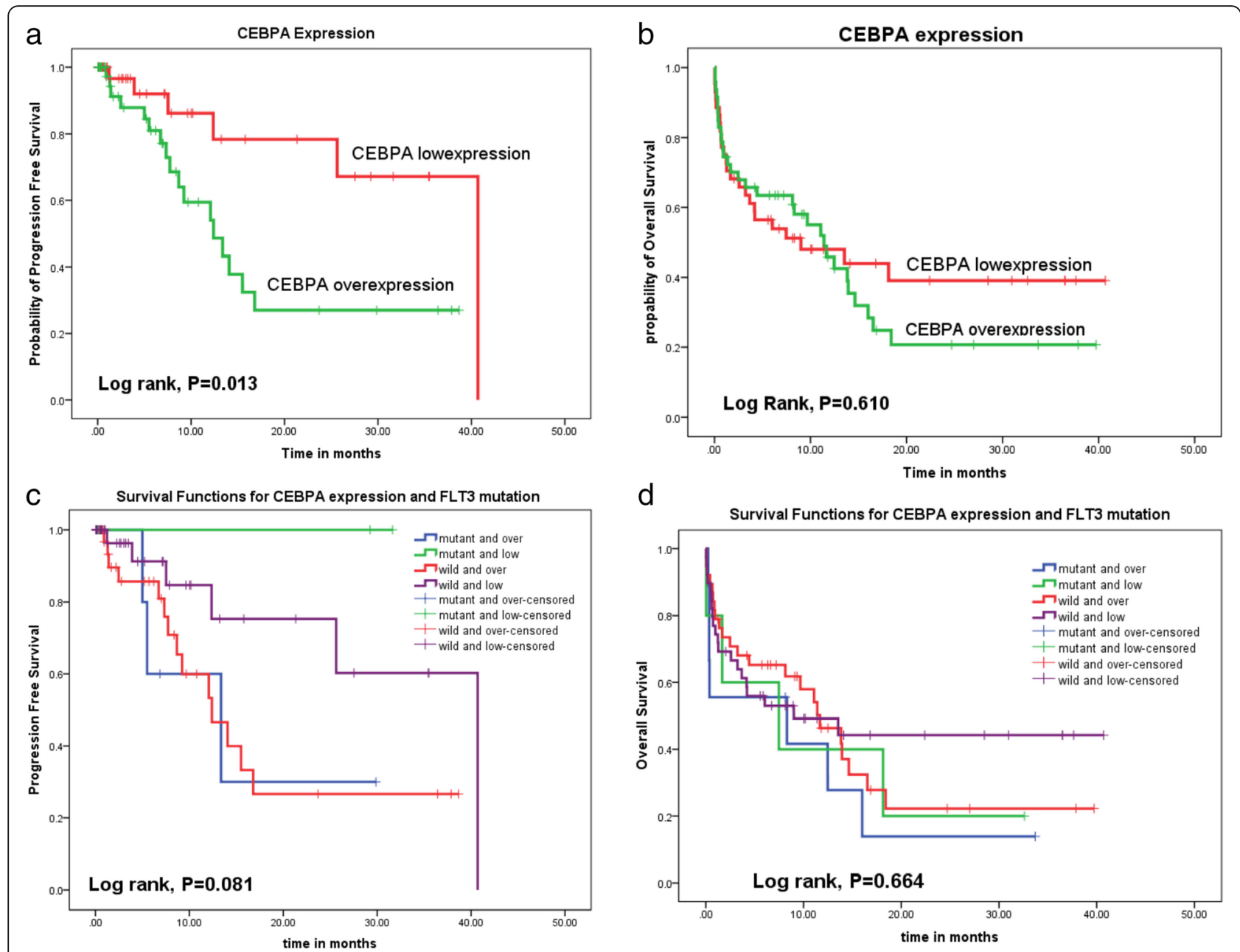

Fig. 3 Impact of CEBPA gene expression on a PFS and $\mathbf{b}$ OS. Impact of CEBPA overexpression and FLT3 mutation on $\mathbf{c}$ disease-free survival and $\mathbf{d}$ overall survival rates

The current study demonstrated that patients with CEBPA overexpression showed a significantly increased total leucocyte count (TLC) and bone marrow hypercellularity, as well as increased percentage of peripheral blood blast cells in the patients. These data are comparable to that reported by D'Alò et al., who demonstrated that low CEBPA expression was observed in patients with leukopenia and decreased expression of CD33 and CD11c antigens at diagnosis [25]. Meanwhile, we could not find a significant association between CEBPA expression and any of the other clinical characteristics assessed including age, sex, cytogenetic risk classification, abnormal karyotyping, organomegaly, lymphadenopathy, and FAB classification. These results are supported by Doorn et al., who reported that $C E B P A$ expression levels had no association with patients' clinical features [15]. Similarly, Salarpour et al. demonstrated that there was no significant association between CEBPA expression and FAB subgroups, which indicates that $C E B P A$ expression level is not dependent on the type of lineage involved (granulocytic vs. monocytic) or levels of cell maturation [23]. However, Gholami et al. observed a significant upregulation of $C E B P A$ in the male AML patients, abnormal karyotype, and FAB subtypes (M0, M3, and M4), as well as in favorable and adverse cytogenetic risk groups [16].

According to our results, there was a significant association between $C E B P A$ expression and progression-free survival rate of the assessed AML patients, while there was no significant association with the overall survival rate. This data is comparable to that of Doorn et al., who observed that CEBPA expression levels had no impact on PFS or OS rates of AML patients, while patients with $C E B P A$ gene $\mathrm{C}$-terminal mutations and frame shift mutations in the $\mathrm{N}$-terminus, showed longer event-free survival (EFS) and OS rates than patients lacking these mutations [15].

Additionally, we found that FLT3-ITD mutation was present in $15.4 \%$ of the assessed patients; this frequency 
is in concordance with $19.8 \%$ FLT3-ITD mutation reported by Wang et al. [27]. An interesting finding in the present study is that all patients who had both CEBPA overexpression and mutant FLT3 showed poor outcomes, since all of them had adverse cytogenetic risk, BM hypercellularity, increased TLC, and PB blast cells count. This is consistent with other published studies reported that FLT3-ITD mutations is a poor prognostic factor associated with refractory disease, increased relapse risk, and poor OS [28-30].

Therefore, the current study provides evidence that CEBPA overexpression may play a role in the progression of AML, though its main function is critically involved in myeloid differentiation; however, our results demonstrated its upregulation in AML. Thus, it is suggested that CEBPA gene is involved in cellular proliferation machinery rather than differentiation during the process of tumorigenesis [23]. Meanwhile, one of the drawbacks in this study is that the assessment of CEBPA gene expression would be helpful if performed in the isolated CD34+ stem/progenitor cells from healthy controls. However, due to the difficulty of obtaining the normal BM samples (donors for BM transplantation), and also the decreasing percentage of CD34+ stem cells $(<5 \%)$, hence, we rely on total BM cells isolated from healthy control subjects.

\section{Conclusion}

We can conclude that CEBPA overexpression could be considered a diagnostic biological marker for AML patients, as well as a poor prognostic factor for disease progression. It has no impact on OS rates of the patients. However, further studies are required on a larger number of patients to assess more deeply the role of its expression dysregulation in AML, and the affected pathways involved in this process. This will open a new avenue for evolving new modalities of treatment targeted to this affected genes and thereby produce better clinical outcomes for those AML patients with CEBPA dysregulation.

\begin{abstract}
Abbreviations
AML: Acute myeloid leukemia; BM: Bone marrow; BMT: Bone marrow transplantation; CEBPA: CCAAT/enhancer binding protein-alpha; EFS: Eventfree survival; ELN: European leukemia net; FAB: French-American-British; FISH: Fluorescence in situ hybridization; FLT3-ITD: Fms-related tyrosine kinase 3; HSCT: Hematopoietic stem cell transplantation; K-EDTA: Potassium ethylene diamine tetra-acetic acid; NMP1: Nucleophosmin 1; OS: Overall survival; PFS: Progression-free survival
\end{abstract}

\section{Acknowledgements}

The authors of the manuscript acknowledge the National Cancer Institute and Cairo University for providing the fund and facilities required to accomplish this work.

\section{Authors' contributions}

$\mathrm{NH}$ put the idea and study design and supervised the work. FS performed the cytogenetics and shared in flow cytometry work and also follow-up of the patients. RS collected data and performed the flow cytometry and molecular work. MS shared in the molecular work and performed the statistical analysis and drafting the manuscript. All authors read and approved the final manuscript.

Funding

This manuscript was funded by National Cancer Institute, Cairo University

\section{Availability of data and materials}

The datasets used and/or analyzed during the current study are available from the corresponding author on reasonable request.

\section{Declarations}

Ethics approval and consent to participate

The research protocol was approved by the Institutional Review Board Ethical Committee of the National Cancer Institute [201617027-4], which follows the rules of the Helsinki Institutional Review Board.

A written informed consent was obtained from all patients and healthy individuals before enrolment in the study.

\section{Consent for publication}

All participants agreed for publication.

\section{Competing interests}

All authors declare no competing interest.

\section{Author details}

${ }^{1}$ Clinical Pathology Department, National Cancer Institute, Cairo University, Cairo 11976, Egypt. ${ }^{2}$ Clinical Pathology Department, Faculty of Medicine, Cairo University, Cairo 11562, Egypt. ${ }^{3}$ Medical Biochemistry and Molecular Biology, Cancer Biology Department, National Cancer Institute, Cairo University, Cairo 11976, Egypt.

Received: 30 October 2020 Accepted: 5 March 2021

Published online: 22 April 2021

\section{References}

1. Chaudhury S, O'Connor C, Canete A et al (2018) Age-specific biological and molecular profiling distinguishes paediatric from adult acute myeloid leukaemias. Nat Commun 9(1):5280. https://doi.org/10.1038/s41467-01807584-1

2. De Kouchkovsky I, Abdul-Hay M (2016) Acute myeloid leukemia: a comprehensive review and 2016 update. Blood Cancer J 6(7):e441. https:// doi.org/10.1038/bcj.2016.50

3. Tomizawa D (2017) Acute leukemia in adolescents and young adults. Rinshoketsueki. 58:2160-2167

4. Akin DF, Oner DA, Kurekci E et al (2018) Determination of CEBPA mutations by next generation sequencing in pediatric acute leukemia. Bratislleklisty. 119:366-372

5. Döhner H, Estey E, Grimwade D et al (2017) Bloomfield CD. Diagnosis and management of AML in adults: 2017 ELN recommendations from an international expert panel. Blood. 129:424-447

6. Ito S, Fujiwara SI, Mashima K, Umino K, Minakata D, Nakano $H_{\text {, }}$ Yamasaki R, Kawasaki Y, Sugimoto M, Ashizawa M, Yamamoto C, Hatano K, Okazuka K, Sato K, Oh I, Ohmine K, Suzuki T, Muroi K, Kanda Y (2017) Development of acute myeloid leukemia in patients with untreated chronic lymphocytic leukemia. Ann Hematol 96(5):719-724. https://doi. org/10.1007/s00277-017-2933-x

7. Tanaka M, Ogasawara H, Nakagawa S, Kamata K, Yamai K, Aisawa H, Yoshihara A, Kimura A, Aoki M, Sasaki T (2016) Effective treatment of a case of acute myeloid leukemia with advanced esophageal cancer. Gan To Kagaku Ryoho 43(11):1405-1408

8. Schlenk RF, Döhner K, Krauter J, Fröhling S, Corbacioglu A, Bullinger L, Habdank M, Späth D, Morgan M, Benner A, Schlegelberger B, Heil G, Ganser A, Döhner H (2008) Mutations and treatment outcome in cytogenetically normal acute myeloid leukemia. N Engl J Med 358(18):1909-1918. https:// doi.org/10.1056/NEJMoa074306

9. Wouters BJ, Löwenberg B, Erpelinck-Verschueren CA et al (2009) Double CEBPA mutations, but not single CEBPA mutations, define a subgroup of acute myeloid leukemia with a distinctive gene expression profile that is uniquely associated with a favorable outcome. Blood. 113(13):3088-3091. https://doi.org/10.1182/blood-2008-09-179895 
10. Taskesen E, Bullinger L, Corbacioglu A, Sanders MA, Erpelinck CAJ, Wouters BJ, van der Poel-van de Luytgaarde SC, Damm F, Krauter J, Ganser A, Schlenk RF, Löwenberg B, Delwel R, Döhner H, Valk PJM, Döhner K (2011) Prognostic impact, concurrent genetic mutations, and gene expression features of AML with CEBPA mutations in a cohort of 1182 cytogenetically normal AML patients: further evidence for CEBPA double mutant AML as a distinctive disease entity. Blood. 117(8):2469-2475. https://doi.org/10.1182/ blood-2010-09-307280

11. Mustafa MI, Mohammed ZO, Murshed NS et al (2019) In silico genetics revealing 5 mutations in CEBPA gene associated with acute myeloid leukemia. Cancer Informatics 18:1176935119870817

12. Kasakura K, Takahashi K, Itoh T, Hosono A, Nunomura S, Ra C, Momose Y, Itoh K, Nishiyama C, Kaminogawa S (2014) C/EBPalpha controls mast cell function. FEBS Lett 588(24):4645-4653. https://doi.org/10.1016/j.febslet.2 014.10 .036

13. Pabst T, Mueller BU (2009) Complexity of CEBPA dysregulation in human acute myeloid leukemia. Clin Cancer Res 15(17):5303-5307. https://doi.org/1 0.1158/1078-0432.CCR-08-2941

14. Radomska HS, Huettner CS, Zhang P, Cheng T, Scadden DT, Tenen DG (1998) CCAAT/enhancer binding protein $a$ is a regulatory switch sufficient for induction of granulocytic development from bipotential myeloid progenitors. Mol Cell Biol 18(7):4301-4314. https://doi.org/1 0.1128/MCB.18.7.4301

15. Van Doorn SBWW, Erpelinck C, Meijer J et al (2003) Biallelic mutations in the CEBPA gene and low CEBPA expression levels as prognostic markers in intermediaterisk AML. Hematol J 4:31-40

16. Gholami M, Bayat S, Manoochehrabadi S et al (2019 Jan) Investigation of CEBPA and CEBPA-AS genes expression in acute myeloid leukemia. Rep Biochem Mol Biol 7:136

17. Swerdlow SH, Campo E, Pileri SA, et al. The 2016 revision of the World Health Organization classification of lymphoid neoplasms. Blood. 2016; 127(20):2375-90

18. Livak KJ, Schmittgen TD (2001) Analysis of relative gene expression data using real time quantitative PCR and the 22DDCT method. Methods 25(4): 402-408. https://doi.org/10.1006/meth.2001.1262

19. McCrum-Gardner $\mathrm{E}$ (2008) Which is the correct statistical test to use? $\mathrm{Br}$ J Oral Maxillofac Surg 46(1):38-41

20. Wang M, Yang C, Zhang L, Schaar DG (2017) Molecular mutations and their cooccurrences in cytogenetically normal acute myeloid leukemia. Stem Cells Int 2017:1-11. https://doi.org/10.1155/2017/6962379

21. Cancer Genome Atlas Research Network (2013 May 30) Genomic and epigenomic landscapes of adult de novo acute myeloid leukemia. New Engl J Med 368(22):2059-2074. https://doi.org/10.1056/NEJMoa1301689

22. Jakobsen JS, Laursen LG, Schuster MB et al (2019) Mutant CEBPA directly drives the expression of the targetable tumor-promoting factor CD73 in AML. Sci Adv 5:eaaw4304

23. Salarpour F, Goudarzipour K, Mohammadi MH, Ahmadzadeh A, Faraahi S, Farsani MA (2017) Evaluation of CCAAT/enhancer binding protein (C/EBP) alpha (CEBPA) and runt-related transcription factor 1 (RUNX1) expression in patients with de novo acute myeloid leukemia. Ann Hum Genet 81(6):276283. https://doi.org/10.1111/ahg.12210

24. Pabst T, Mueller BU, Harakawa N, Schoch C, Haferlach T, Behre G, Hiddemann W, Zhang DE, Tenen DG (2001) AML1-ETO downregulates the granulocytic differentiation factor C/EBP[alpha] in t(8;21) myeloid leukemia. Nat Med 7(4):444-451. https://doi.org/10.1038/86515

25. D'Alò F, Di Ruscio A, Guidi F et al (2008) PU. 1 and CEBPA expression in acute myeloid leukemia. Leuk Res 32(9):1448-1453. https://doi.org/10.1016/j. leukres.2008.01.007

26. Grossmann V, Bacher U, Kohlmann A, Butschalowski K, Roller A, Jeromin S, Dicker F, Kern W, Schnittger S, Haferlach T, Haferlach C (2012) Expression of CEBPA is reduced in RUNX1-mutated acute myeloid leukemia. Blood Cancer J 2(8):e86. https://doi.org/10.1038/bcj.2012.34

27. Wang J, Ma Z, Wang Q, Guo Q, Huang J, Yu W, Wang H, Huang J, Washington Shao Y, Chen S, Jin J (2018) Prognostic utility of six mutated genes for older patients with acute myeloid leukemia. Int J Cancer 142(8): 1664-1670. https://doi.org/10.1002/ijc.31178

28. Stirewalt DL, Kopecky KJ, Meshinchi S, Engel JH, Pogosova-Agadjanyan EL, Linsley J, Slovak ML, Willman CL, Radich JP (2006) Size of FLT3 internal tandem duplication has prognostic significance in patients with acute myeloidleukemia. Blood. 107(9):3724-3726. https://doi.org/10.1182/blood-2 005-08-3453
29. Schlenk RF, Kayser S, Bullinger L, et al. Differential impact of allelic ratio and insertion site in FLT3-ITD-positive AML with respect to allogeneic transplantation. Blood. 2014;124(23):3441-9.

30. Fischer T, Stone RM, DeAngelo DJ et al (2010) Phase IIB trial of oral Midostaurin (PKC412), the FMS-liketyrosine kinase 3 receptor (FLT3) and multi-targeted kinase inhibitor in patients with acute myeloid leukemia and high-riskmyelodysplastic syndrome with either wild-type or mutated FLT3. J Clin Oncol 28:4339

\section{Publisher's Note}

Springer Nature remains neutral with regard to jurisdictional claims in published maps and institutional affiliations.

\section{Submit your manuscript to a SpringerOpen ${ }^{\circ}$ journal and benefit from:}

- Convenient online submission

- Rigorous peer review

- Open access: articles freely available online

- High visibility within the field

- Retaining the copyright to your article

Submit your next manuscript at $\boldsymbol{\nabla}$ springeropen.com 